\title{
Characteristics of Critically-III Patients at Two Tertiary Care Hospitals in Sudan
}

\author{
"Hagir Sulieman, ${ }^{1}$ Wael El-Mahdi, ${ }^{2}$ Mohannad Awadelkareem, ${ }^{2}$ Lama Nazer ${ }^{3}$
}

\section{خصائص المرضى المصابين بحالات حرجة بمستشفيات الرعاية الثالثية في السودان}

\author{
هـاجر سليمان، وائل المهدي، مهند عوضالكريم، لمى الناظر
}

ABSTRACT: Objectives: Knowledge of intensive care unit (ICU) admission patterns and characteristics is necessary for the development of critical care services, particularly in low-resource settings. This study aimed to describe the characteristics of critically-ill patients admitted to ICUs in Sudan. Methods: This prospective observational study was conducted between February and May 2017 in the ICUs of two government tertiary care hospitals in Khartoum, Sudan. A total of 100 consecutive adult patients admitted to the ICUs were included in the study. The patients' demographic and clinical characteristics and Acute Physiologic Assessment and Chronic Health Evaluation (APACHE II) scores upon admission were recorded, as well as the reason for admission, presence of any underlying comorbidities, interventional requirements like mechanical ventilation or haemodialysis, length of stay in the ICU and patient outcome. Results: Of the sample, $58 \%$ were female and $42 \%$ were male. The mean age was $47.4 \pm 18.3$ years old. Upon admission, the mean APACHE II score was $14.2 \pm 9.6$. In total, $54 \%$ of the patients had no known underlying comorbidities. The most common reasons for ICU admission were neurological diseases (27\%), sepsis or infectious diseases (19\%) and postoperative management (12\%). Mechanical ventilation and haemodialysis were required by $35 \%$ and $11 \%$ of the patients, respectively. The average length of stay was $10.0 \pm 7.2$ days and the mortality rate was $24 \%$. Conclusion: Most of the patients admitted to the ICUs were middle-aged females with no known underlying comorbidities. Larger studies are necessary to provide a comprehensive understanding of the critical care needs of Sudanese hospitals.

Keywords: Intensive Care Units; Patient Admission, trends; Critical Care Outcomes; Developing Countries; Sudan.

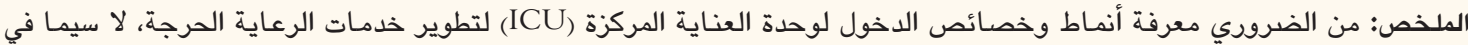

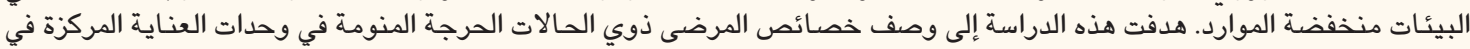

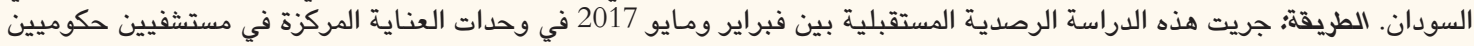

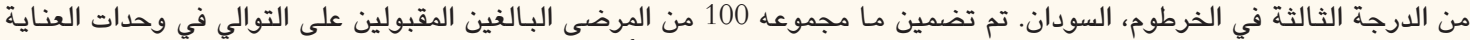

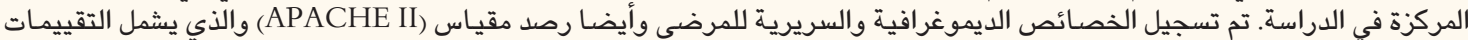

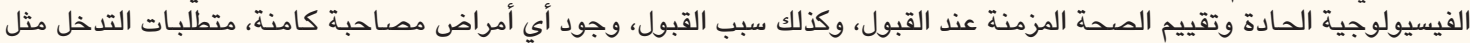

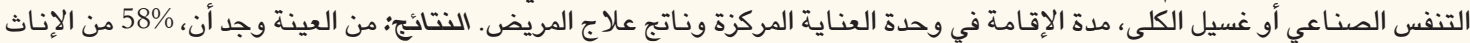

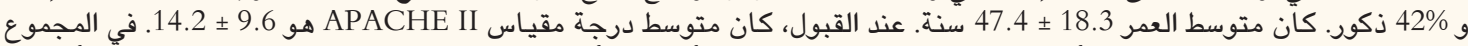

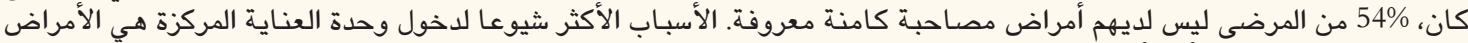

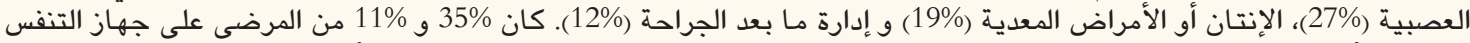

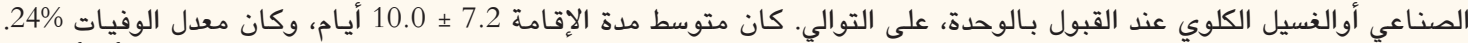

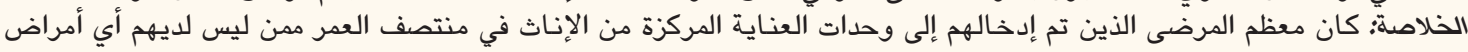

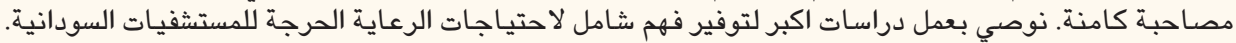

الكلمات المفتاحية: وحدات العناية المركزة قبول المرضى؛ قبول المرضى، الاتجاهـات؛ نتائج الرعاية الحرجة؛ الدول النامية؛ السودان.

\section{AdVANCES IN KNOWLEDGE}

To the best of the authors' knowledge, this study is the first to describe the characteristics and outcomes of critically-ill patients in Sudan.

Most patients admitted to the intensive care units (ICUs) of two major tertiary government hospitals in Sudan were middle-aged females. The most frequent reasons for ICU admission were neurological disorders and sepsis or infectious diseases. The average length of stay was relatively high and the mortality rate was $24 \%$.

\section{Application to Patient Care}

Characterising patients who require critical care is essential to identify areas that need improvement. The findings of this study provide a general understanding of the type of patients managed in two ICUs in Sudan and highlights areas that may need to be addressed.

NTENSIVE CARE UNITS (ICUs) WERE FIRST introduced over half a century ago; since then, critical care medicine has progressed significantly worldwide, particularly in industrialised developed countries, resulting in significant improvements in the quality of care and outcomes of critically-ill patients. ${ }^{1-3}$ 
However, in developing countries such as those in subSaharan Africa, critical care medicine has evolved at a considerably slower pace. ${ }^{4,5}$ Moreover, hospitals in these countries often cannot fully implement wellestablished standards of care in ICUs due to limited financial resources and lack of equipment, medications and trained clinical staff. ${ }^{4-6}$ Proposed strategies to improve critical care services in developing countries include incorporating a structured critical care training programme, increasing the nursing workforce and collecting data regarding patient outcomes. ${ }^{6}$

Sudan has a population of approximately 40 million people, of which nine million reside in the capital of Khartoum. ${ }^{7}$ All four tertiary care hospitals in Khartoum have government-funded critical care units which serve the entire country; however, these 74-bed ICUs are almost fully occupied year-round. The facilities and services available at the ICUs of all four government tertiary hospitals in Khartoum are listed in Table 1. While a few government-operated ICUs outside of Khartoum have been developed recently, these ICUs generally have limited bed capacity, equipment and critical care specialists. Although nongovernmental critical care units are available at teaching and private institutions, these also have a limited number of beds. At the Khartoum North Hospital and Ibrahim Malik Hospital, two of the four tertiary care hospitals in Khartoum, approximately 700 adult patients are admitted each month; the former serves northern Khartoum and the surrounding area, while the latter receives patients from all over the country. Most neurological cases from outside Khartoum are also referred to the Ibrahim Malik Hospital for both critical and non-critical care.

At the 17-bed ICU of the Khartoum North Hospital, there are approximately 25-35 admissions per month. The ICU operates on an open admission policy, so that any physician at Khartoum North Hospital may admit a patient to the unit and thereafter manage the patient during their ICU stay. While the ICU itself does not have a haemodialysis machine, patients who require dialysis can be referred elsewhere within the hospital. In addition, although the hospital does not have arterial blood gas analysis facilities, blood samples from ICU patients are transported to a nearby laboratory for immediate analysis. At the 7-bed ICU of the Ibrahim Malik Hospital, there are approximately 15-20 admissions per month. A semi-closed system is used, in which an intensive care consultant is responsible for ICU patients, conducts daily rounds and discusses patient management with the primary team.

Despite the expansion of critical care services in Sudan over the past decade, the characteristics and outcomes of critically-ill patients at governmental
Table 1: Characteristics of intensive care units at governmental tertiary care hospitals in Khartoum, Sudan

\begin{tabular}{|c|c|c|c|c|}
\hline Characteristic & AFH & ОТн & KNH & IMH \\
\hline \multicolumn{5}{|l|}{ Capacity } \\
\hline $\begin{array}{l}\text { Number of hospital } \\
\text { beds }\end{array}$ & 550 & 500 & 400 & 287 \\
\hline $\begin{array}{l}\text { Number of ICU } \\
\text { beds }\end{array}$ & 40 & 10 & 17 & 7 \\
\hline $\begin{array}{l}\text { ICU admission } \\
\text { system }\end{array}$ & $\begin{array}{l}\text { Semi- } \\
\text { closed }\end{array}$ & $\begin{array}{l}\text { Semi- } \\
\text { closed }\end{array}$ & Open & $\begin{array}{l}\text { Semi- } \\
\text { closed }\end{array}$ \\
\hline \multicolumn{5}{|l|}{ Equipment } \\
\hline $\begin{array}{l}\text { Number of } \\
\text { mechanical } \\
\text { ventilators }\end{array}$ & 40 & 10 & 7 & 7 \\
\hline $\begin{array}{l}\text { Number of arterial } \\
\text { blood gas machines }\end{array}$ & 1 & 1 & 0 & 1 \\
\hline $\begin{array}{l}\text { Number of dialysis } \\
\text { machines }\end{array}$ & 1 & 1 & 0 & 1 \\
\hline $\begin{array}{l}\text { Number of } \\
\text { portable X-ray } \\
\text { machines }\end{array}$ & 1 & 1 & 0 & 1 \\
\hline $\begin{array}{l}\text { Number of } \\
\text { bedside ultrasound } \\
\text { machines }\end{array}$ & 1 & 1 & 1 & 1 \\
\hline \multicolumn{5}{|l|}{ Staffing } \\
\hline Nurse-to-bed ratio & $1: 1$ & $1: 1$ & $1: 2$ & $1: 1$ \\
\hline $\begin{array}{l}\text { Number of ICU } \\
\text { consultants }\end{array}$ & 5 & 3 & 0 & 1 \\
\hline $\begin{array}{l}\text { Number of ICU } \\
\text { clinical pharmacists }\end{array}$ & 1 & 3 & 1 & 1 \\
\hline $\begin{array}{l}\text { Number of } \\
\text { ICU respiratory } \\
\text { therapists }\end{array}$ & 3 & 0 & 0 & 0 \\
\hline $\begin{array}{l}\text { Number of ICU } \\
\text { medical residents } \\
\text { per day }\end{array}$ & $6-8$ & 2 & 3 & 2 \\
\hline
\end{tabular}

AFH = Armed Forces Hospital; OTH = Omdurman Teaching Hospital; $K N H=$ Khartoum North Hospital; IMH = Ibrahim Malik Hospital; $I C U=$ intensive care unit.

tertiary care hospitals have not yet been studied. This information is essential for guiding admission and discharge policies and estimating the resources necessary for managing these patients. ${ }^{6}$ This study therefore aimed to describe the characteristics of critically-ill adults admitted to the ICUs of the Khartoum North Hospital and Ibrahim Malik Hospital.

\section{Methods}

This prospective observational study was conducted between February and May 2017 at the Khartoum North Hospital and Ibrahim Malik Hospital. The sample consisted of consecutive $\geq 16$-year-old patients admitted to the ICUs of these hospitals during the 
Table 2: Characteristics of patients admitted to the intensive care units of the Khartoum North Hospital and Ibrahim Malik Hospital in Khartoum, Sudan $(\mathrm{N}=100)$

\begin{tabular}{|c|c|}
\hline Characteristic & n (\%) \\
\hline \multicolumn{2}{|l|}{ Gender } \\
\hline Female & $58(58)$ \\
\hline Male & $42(42)$ \\
\hline Mean age in years \pm SD & $47.4 \pm 18.3$ \\
\hline \multicolumn{2}{|l|}{ Place of residence } \\
\hline Khartoum & $75(75)$ \\
\hline Elsewhere & $25(25)$ \\
\hline Mean APACHE II score \pm SD & $14.2 \pm 9.6$ \\
\hline \multicolumn{2}{|l|}{ Presence of comorbidities } \\
\hline Yes & $46(46)$ \\
\hline No & $54(54)$ \\
\hline \multicolumn{2}{|l|}{ Type of comorbidity* } \\
\hline Diabetes & $28(60.9)$ \\
\hline Hypertension & $24(52.2)$ \\
\hline CAD & $3(6.5)$ \\
\hline Asthma/COPD & $6(13)$ \\
\hline Renal disease & $7(15.2)$ \\
\hline Other & $3(6.5)$ \\
\hline \multicolumn{2}{|l|}{ Location prior to ICU admission } \\
\hline Emergency department & $50(50)$ \\
\hline Hospital ward & $24(24)$ \\
\hline Operating theatre & $8(8)$ \\
\hline Other hospital & $18(18)$ \\
\hline \multicolumn{2}{|l|}{ Reason for admission } \\
\hline Neurological disorders & $27(27)$ \\
\hline Sepsis/infectious diseases & $19(19)$ \\
\hline Postoperative management & $12(12)$ \\
\hline Cardiac disorders & $8(8)$ \\
\hline Respiratory failure & $8(8)$ \\
\hline Renal failure & $8(8)$ \\
\hline DKA & $7(7)$ \\
\hline Other & $11(11)$ \\
\hline \multicolumn{2}{|l|}{ Intervention requirements } \\
\hline Mechanical ventilation & $35(35)$ \\
\hline Tracheostomy & $9(9)$ \\
\hline Haemodialysis & $11^{\dagger}(11)$ \\
\hline \multicolumn{2}{|c|}{ Medications prescribed during ICU stay* } \\
\hline Antibiotics & $100(100)$ \\
\hline Pain medications & $42(42)$ \\
\hline Antihypertensives & $25(25)$ \\
\hline Vasopressors & $19(19)$ \\
\hline Sedatives & $30(30)$ \\
\hline Muscle relaxants & $2(2)$ \\
\hline Thrombolytics & $1(1)$ \\
\hline H2 blockers/PPIs & $100(100)$ \\
\hline
\end{tabular}

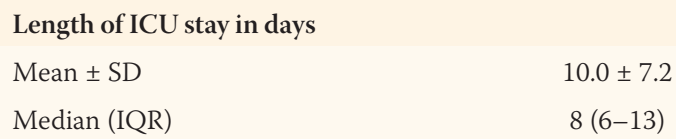

$S D=$ standard deviation $;$ APACHE II = Acute Physiologic Assessment and Chronic Health Evaluation; $C A D=$ coronary artery disease; $C O P D=$ chronic obstructive pulmonary disease; $I C U=$ intensive care unit; $D K A$ = diabetic ketoacidosis; $P P I=$ proton pump inhibitor $I \mathrm{QR}=$ interquartile range.

"Percentages do not add up to 100\% as some patients may have been included in more than one category. ${ }^{\dagger} \mathrm{O}$ f these patients, four required dialysis due to acute renal failure and seven due to chronic renal failure.

study period until a total of 100 patients had been included. Patients were enrolled in the study by two medical officers who worked 24 hours per week in the ICU of the hospitals. Patients admitted consecutively on the days on which the medical officers were on duty were included, while patients admitted on days that neither medical officer was available were excluded.

The demographic and clinical characteristics of the patients were recorded by the two medical officers upon admission to the ICU. In addition, the reason for admission, admitting department, presence of any underlying comorbidities, need for interventions (i.e. mechanical ventilation and haemodialysis), length of stay in the ICU and mortality rate were also noted. In each case, the Acute Physiologic Assessment and Chronic Health Evaluation (APACHE II) score was determined using the worst/most severe measurements of various physiological and laboratory parameters recorded during the first 24 hours of admission. ${ }^{8}$

Data were analysed using the Statistical Analysis System program, Version 9.4 (SAS Institute, Cary, North Carolina, USA). Descriptive data were presented as counts and percentages for categorical data and means and standard deviations or medians and interquartile ranges for continuous data. Either a Chi-squared test or Fisher's exact test was used to compare categorical variables, as appropriate, while the Kruskal-Wallis test was used for continuous variables. A $P$ value of $\leq 0.05$ was deemed statistically significant.

The institutional review boards of both the Khartoum North Hospital and the Ibrahim Malik Hospital approved the protocols of this study. The need for informed patient consent was waived as all data included in the analysis were deidentified.

\section{Results}

Table 2 outlines the demographic and clinical characteristics of the study cohort. Most of the patients admitted to the ICUs of the Khartoum North Hospital and Ibrahim Malik Hospital were female (58\%) and 
Table 3: Comparison of characteristics affecting survival among patients admitted to the intensive care units of the Khartoum North Hospital and Ibrahim Malik Hospital in Khartoum, Sudan $(\mathrm{N}=100)$

\begin{tabular}{|c|c|c|c|}
\hline \multirow[t]{2}{*}{ Characteristic } & \multicolumn{2}{|c|}{ n (\%) } & \multirow[t]{2}{*}{$P$ value } \\
\hline & $\begin{array}{l}\text { Survivors } \\
(\mathrm{n}=76)\end{array}$ & $\begin{array}{c}\text { Non- } \\
\text { survivors } \\
(\mathrm{n}=24)\end{array}$ & \\
\hline \multicolumn{4}{|l|}{ Gender } \\
\hline Female & $44(57.9)$ & $14(58.3)$ & \multirow{2}{*}{0.99} \\
\hline Male & $32(42.1)$ & $10(41.7)$ & \\
\hline $\begin{array}{l}\text { Mean age in years } \\
\pm S D\end{array}$ & $45.6 \pm 17.8$ & $47.9 \pm 18.5$ & 0.57 \\
\hline \multicolumn{4}{|l|}{ Place of residence } \\
\hline Khartoum & $69(90.8)$ & $6(25)$ & \multirow[b]{2}{*}{$<0.01$} \\
\hline Elsewhere & $7(9.2)$ & $18(75)$ & \\
\hline $\begin{array}{l}\text { Mean APACHE II } \\
\text { score } \pm \text { SD }\end{array}$ & $12.5 \pm 8.8$ & $18.6 \pm 9.7$ & 0.02 \\
\hline \multicolumn{4}{|c|}{ Presence of comorbidities } \\
\hline Yes & $35(46.1)$ & $11(45.8)$ & \multirow{2}{*}{0.99} \\
\hline No & $41(53.9)$ & $13(54.2)$ & \\
\hline \multicolumn{4}{|c|}{ Type of comorbidity* } \\
\hline Diabetes & $21(60)$ & $7(63.6)$ & 0.88 \\
\hline Hypertension & $19(54.3)$ & $5(45.5)$ & 0.99 \\
\hline CAD & $3(8.6)$ & $0(0)$ & 0.32 \\
\hline Asthma/COPD & $4(11.4)$ & $2(18.2)$ & 0.66 \\
\hline Renal disease & $6(17.1)$ & $1(9.1)$ & 0.53 \\
\hline Other & $1(2.9)$ & $2(18.2)$ & - \\
\hline \multicolumn{4}{|c|}{ Location prior to ICU admission } \\
\hline $\begin{array}{l}\text { Emergency } \\
\text { department }\end{array}$ & $36(47.4)$ & $14(58.3)$ & \multirow{4}{*}{$0.39^{\dagger}$} \\
\hline Hospital ward & $21(27.6)$ & $3(12.5)$ & \\
\hline Operating theatre & $5(6.6)$ & $3(12.5)$ & \\
\hline Other hospital & $14(18.4)$ & $4(16.7)$ & \\
\hline \multicolumn{4}{|c|}{ Reason for admission } \\
\hline $\begin{array}{l}\text { Neurological } \\
\text { disorders }\end{array}$ & $21(27.6)$ & $6(25)$ & \multirow{8}{*}{0.13} \\
\hline $\begin{array}{l}\text { Sepsis/infectious } \\
\text { diseases }\end{array}$ & $11(14.5)$ & $8(33.3)$ & \\
\hline $\begin{array}{l}\text { Postoperative } \\
\text { management }\end{array}$ & $11(14.5)$ & $1(4.2)$ & \\
\hline Cardiac disorders & $4(5.3)$ & $4(16.7)$ & \\
\hline $\begin{array}{l}\text { Respiratory } \\
\text { failure }\end{array}$ & $7(9.2)$ & $1(4.2)$ & \\
\hline Renal failure & $8(10.5)$ & $0(0)$ & \\
\hline DKA & $6(7.9)$ & $1(4.2)$ & \\
\hline Other & $8(10.5)$ & $3(12.5)$ & \\
\hline \multicolumn{4}{|c|}{ Intervention requirements } \\
\hline $\begin{array}{l}\text { Mechanical } \\
\text { ventilation }\end{array}$ & $21(27.6)$ & $14(58.3)$ & $<0.01$ \\
\hline Tracheostomy & $7(9.2)$ & $2(8.3)$ & 0.94 \\
\hline Haemodialysis & $10^{\ddagger}(13.2)$ & $1^{\S}(4.2)$ & 0.11 \\
\hline
\end{tabular}

\begin{tabular}{lcc}
\multicolumn{4}{l}{ Medications prescribed during ICU sta ${ }^{* \mathbf{*}} \mathbf{l}$} \\
Antibiotics & $76(100)$ & $24(100)$ \\
Pain medications & $24(31.6)$ & $18(75)$ \\
Antihypertensives & $20(26.3)$ & $5(20.8)$ \\
Vasopressors & $7(9.2)$ & $12(50)$ \\
Sedatives & $17(22.4)$ & $13(54.2)$ \\
Muscle relaxants & $0(0)$ & $2(8.3)$ \\
Thrombolytics & $0(0)$ & $1(4.2)$ \\
H2 blockers/PPIs & $76(100)$ & $24(100)$ \\
Length of ICU stay in days & \\
Mean \pm SD & $11.8 \pm 11.2$ & $10.5 \pm 12.6$ \\
Median (IQR) & $8(7-14)$ & $6(4-10)$
\end{tabular}

$S D=$ standard deviation $;$ APACHE II = Acute Physiologic Assessment and Chronic Health Evaluation: $C A D=$ coronary artery disease: $C O P D=$ chronic obstructive pulmonary disease; $I C U=$ intensive care unit; $D K A$ = diabetic ketoacidosis; $P P I=$ proton pump inhibitor; $I Q R=$ interquartile range.

"Percentages do not add up to $100 \%$ as some patients may have been included in more than one category. ${ }^{\dagger}$ Each variable was statistically compared with the other variables combined. ${ }^{\ddagger}$ Of these patients, three had acute renal failure and seven had chronic renal failure. ${ }^{5}$ This patient had acute renal failure. $A$ statistical comparison was not possible for this variable as patients received multiple combinations of medications throughout their ICU stay.

residents of Khartoum (75\%). The mean age was $47.4 \pm 18.3$ years old and the mean APACHE II score was $14.2 \pm 9.6$. The majority of patients (54\%) had no identifiable comorbidities prior to ICU admission. Of those with comorbidities, the most common were diabetes (60.9\%) and hypertension (52.2\%). Although none of the patients had a history of cancer, two patients were diagnosed with cancer during their ICU stay. Half of the patients were admitted from the emergency department; of these, 16\% had neurological disorders, $16 \%$ had sepsis and 10\% had respiratory illnesses. Overall, the most common reason for ICU admission was a neurological disorder (27\%), with haemorrhagic and ischaemic strokes diagnosed in five (18.5\%) and eight (29.6\%) of these patients, respectively. Following this, $19 \%$ were admitted due to sepsis or infectious diseases and $12 \%$ for post-surgical management.

All of the patients were prescribed antibiotics and $\mathrm{H} 2$ blockers at some point during their ICU stay. About one-third of the patients (35\%) required mechanical ventilation at the time of admission. All of these patients received continuous infusions of analgaesics and sedatives during intubation, with two patients (5.7\%) requiring a muscle relaxant as well. Furthermore, $11 \%$ of the patients required dialysis during their stay; of these, four patients (36.4\%) were diagnosed with acute renal failure during their ICU stay, while seven $(63.6 \%)$ had chronic renal failure and were on dialysis prior to ICU admission. The mean length of stay in the ICU was $10.0 \pm 7.2$ days. 
The overall mortality rate of the study cohort was $24 \%$. Table 3 compares the characteristics of the survivors and non-survivors. The non-survivors had significantly higher APACHE II scores upon ICU admission compared to the survivors $(18.6 \pm 9.7$ versus $12.5 \pm 8.8 ; P=0.02)$. Moreover, significantly more of the non-survivors required mechanical ventilation compared to the survivors $(58.3 \%$ versus $27.6 \%$; $P<0.01)$. In addition, among the non-survivors, significantly more patients resided outside Khartoum compared to the survivors (75\% versus $9.2 \%$; $P<0.01$ ).

\section{Discussion}

To the best of the authors' knowledge, this study is the first to evaluate the characteristics and outcomes of critically-ill patients admitted to ICUs in Sudan. Previous research published on the patterns and outcomes of patients admitted to ICUs in other subSaharan countries, including Benin, Nigeria, Tanzania and Uganda, indicated wide variations in disease characteristics and mortality rates. ${ }^{9-14}$ Moreover, it is to be expected that the characteristics and outcomes of patients admitted to ICUs in developing countries will differ from those in industrialised countries due to vast differences in diseases patterns and the available healthcare infrastructure and resources. Dünser et al. reported significant differences in patient characteristics, ICU practices and patient outcomes at the ICUs of a 400-bed tertiary care university hospital in Mongolia and a 429-bed hospital in Austria. ${ }^{15}$ Specifically, patients admitted to the ICU in Mongolia had fewer chronic diseases, more frequently presented with tuberculosis and did not receive medical care prior to ICU admission. Moreover, the overall mortality rate was significantly higher $(19.7 \%$ versus 6.2\%; $P<0.001) .{ }^{15}$

In the present study, the most common reason for ICU admission was neurological disorders, such as a stroke, followed by sepsis/infectious diseases and postoperative management. In an earlier study of obstetric and gynaecological admissions to the ICU at Khartoum Hospital, the most common reasons for ICU admission were eclampsia (44.8\%) and postpartum haemorrhage (31.3\%) among obstetric cases and infections (59.3\%) and ovarian or cervical cancer (18.7\%) among gynaecological cases. ${ }^{16}$ In their review of critical care services in the least developed countries worldwide, Dünser et al. found the commonest reasons for admission to the ICU to be post-surgical treatment, infectious diseases, trauma and peripartum maternal or neonatal complications. ${ }^{5}$ The higher incidence of neurological-related disorders in the current study may partly be due to the fact that the emergency room of the Ibrahim Malik Hospital is also shared by the National Center for Neuroscience in Sudan; thus, neurological patients referred to this centre and requiring critical care would be admitted to the hospital's ICU.

Almost one-fourth of the patients in the current study died during their ICU stay. Although this mortality rate was lower than that reported for other populations of critically-ill patients in sub-Saharan countries (range: 27-64\%), it was nevertheless higher than the predicted mortality rate based on the mean APACHE II score upon ICU admission $(\approx 15 \%){ }^{8-14,17}$ Although the exact reason for this higher mortality rate is unclear, several factors may have contributed to this outcome. First, it is possible that there was a delay in providing therapy for some patients. Second, no comorbidities were recorded for over half of the cohort; certain patients may hence have had unidentified underlying diseases that went untreated prior to admission. Finally, despite having been admitted to the ICU with less severe conditions and therefore lower APACHE II scores, some patients may have developed complications during their stay, worsening their condition. The latter possibility is supported by the relatively long mean ICU stay, which is generally reflective of patients with ongoing critical conditions requiring continued ICU services.

In the current study, factors which were found to significantly affect mortality included higher APACHE II scores upon ICU admission, the need for mechanical ventilation and residing outside Khartoum. In particular, the latter finding is concerning and raises questions regarding the potentially less-than-timely management of critically-ill patients in more rural parts of Sudan, as well as the necessity of ensuring the availability of ICU equipment and critical care personnel. Future research is recommended to identify other factors related to mortality rates in ICUs in Sudan so as to improve patient outcomes. Medical care for patients presenting to government hospitals in Sudan is cheaper than for private hospitals and medical fees are usually waived for patients who are unable to pay; thus, the ability to pay is not a factor in determining ICU admission patterns or mortality rates.

This study was limited by its relatively small sample size and the inclusion of only two out of the four government tertiary hospitals in Khartoum. Unfortunately, due to logistical issues with the data collection process, it was not possible to include the other two government hospitals, the Armed Forces Hospital and Omdurman Teaching Hospital. Therefore, the study was conducted solely in the hospitals at which two of the authors worked. Nevertheless, as 
all four hospitals serve the entire country, critically-ill patients admitted to the Khartoum North Hospital and Ibrahim Malik Hospital may be considered nationally representative of this patient population.

\section{Conclusion}

This study provides insight into the characteristics and outcomes of ICU admissions at two government hospitals in Khartoum. More than half of the patients were middle-aged females, with the majority having no known underlying comorbidities. The overall mortality rate was $24 \%$. Large multicentre studies are necessary to form a comprehensive understanding of the critical care needs in Sudan; these findings would help guide the national healthcare system in formulating policies to improve and increase the capacity of current critical care services.

\section{ACKNOWLEDGMENTS}

The authors are grateful to the members of the Critical Care Research Academy for their valuable mentorship while conducting this research project, with special thanks to Dr. Abdulrazaq Al-Jazairi and Dr. Elisabeth Heseltine for their help in reviewing and editing the manuscript. The authors also wish to thank Dr. A. Al-Muhaimen, Dr. Mohammed Al-Amin and Dr. Omima Shihabeldin for helping with the data analysis.

\section{CONFLICT OF INTEREST}

The authors declare no conflicts of interest.

\section{FUNDING}

No funding was received for this study.

\section{References}

1. Berthelsen PG, Cronqvist M. The first intensive care unit in the world: Copenhagen 1953. Acta Anaesthesiol Scand 2003; 47:1190-5. doi: 10.1046/j.1399-6576.2003.00256.x.

2. Vincent JL, Creteur J. Paradigm shifts in critical care medicine: The progress we have made. Crit Care 2015; 19:S10. doi: 10.11 $86 /$ cc14728

3. Grenvik A, Pinsky MR. Evolution of the intensive care unit as a clinical center and critical care medicine as a discipline. Crit Care Clin 2009; 25:239-50. doi: 10.1016/j.ccc.2008.11.001.
4. Baelani I, Jochberger S, Laimer T, Otieno D, Kabutu J, Wilson I, et al. Availability of critical care resources to treat patients with severe sepsis or septic shock in Africa: A self-reported, continent-wide survey of anaesthesia providers. Crit Care 2011; 15:R10. doi: 10.1186/cc9410.

5. Dünser MW, Baelani I, Ganbold L. A review and analysis of intensive care medicine in the least developed countries. Crit Care Med 2006; 34:1234-42. doi: 10.1097/01.CCM.0000 208360.70835.87.

6. Haniffa R, Pubudu De Silva A, de Azevedo L, Baranage D, Rashan A, Baelani I, et al. Improving ICU services in resourcelimited settings: Perceptions of ICU workers from low-middle-, and high-income countries. J Crit Care 2018; 44:352-6. doi: 10.1016/j.jcrc.2017.12.007.

7. World Bank. Sudan. From: https://data.worldbank.org/country/ Sudan Accessed: Mar 2018.

8. Knaus WA, Draper EA, Wagner DP, Zimmerman JE. APACHE II: A severity of disease classification system. Crit Care Med 1985; 13:818-29.

9. Adudu OP, Adudu OG. Working practices and patient outcome in the intensive care unit of the University of Benin Teaching Hospital. J Med Biomed Res 2004; 3:67-72. doi: 10.4314/jmbr. v4i1.10668.

10. Isamade ES, Yiltok SJ, Uba AF, Isamade EI, Daru PH. Intensive care unit admissions in the Jos University Teaching Hospital. Niger J Clin Pract 2007; 10:156-61.

11. Merah NA, Okeke CI, Olatosi JO. An audit of surgical admissions to the intensive care unit of the Lagos University Teaching Hospital (1997 - 2002). Niger Postgrad Med J 2006; 13:153-6.

12. Sawe HR, Mfinanga JA, Lidenge SJ, Mpondo BC, Msangi S, Lugazia E, et al. Disease patterns and clinical outcomes of patients admitted in intensive care units of tertiary referral hospitals of Tanzania. BMC Int Health Hum Rights 2014; 14:26. doi: 10.1186/1472-698X-14-26.

13. Kwizera A, Dünser M, Nakibuuka J. National intensive care unit bed capacity and ICU patient characteristics in a low income country. BMC Res Notes 2012; 5:475. doi: 10.1186/1756-0500$5-475$.

14. Dünser MW, Towey RM, Amito J, Mer M. Intensive care medicine in rural sub-Saharan Africa. Anaesthesia 2017; 72:181-9. doi: $10.1111 /$ anae.13710.

15. Dünser MW, Bataar O, Tsenddorj G, Lundeg G, Torgersen C, Romand JA, et al. Differences in critical care practice between an industrialized and a developing country. Wien Klin Wochenschr 2008; 120:600-7. doi: 10.1007/s00508-008-1064-8.

16. Ibrahim IA, Rayis DA, Alsammani MA, Adam I. Obstetric and gynecologic admissions to the intensive care unit at Khartoum Hospital, Sudan. Int J Gynaecol Obstet 2015; 129:84. doi: 10.1016/j.ijgo.2014.10.019.

17. Ouédraogo N, Niakara A, Simpore A, Barro S, Ouédraogo H, Sanou J. [Intensive care in Africa: A report of the first two years of activity of the intensive care unit of Ouagadougou National Hospital (Burkina Faso)]. Sante 2002; 12:375-82. 